\title{
DIREITO DAS OBRIGAÇÕES: OBRIGAÇÃO DE FAZER E NÃO FAZER
}

\author{
Adriel Prado de Oliveira, Lucas César Bonato Ros, Ricardo Gabriel de Araújo \\ Universidade do Oeste Paulista - UNOESTE, curso de Direito, Presidente Prudente,SP. E-mail: \\ adriel prado@hotmail.com; lucas.b ros@hotmail.com; ricardoaraujo@unoeste.br
}

\section{RESUMO}

O presente artigo tem como objetivo apresentar uma reflexão sobre a importância dos Direitos Obrigacionais diante da sociedade, especificadamente o direito de fazer e não fazer. Abordar-seão os conceitos e quando se aplica os referidos direitos, tendo por objetivo demostrar a complexidade e importância destes direitos em nossa sociedade contemporânea tanto quanto a garantia que este traz. A metodologia consignou de pesquisas bibliográficas. Os dados impetrados foram ponderados utilizando-se do método hipotético dedutivo. Conclui-se que o direito de fazer e não fazer são garantias de cumprimento do que lhe é devido de direito por norma competente.

Palavras-Chave: Obrigação de Fazer e Não Fazer, Importância, Direito Obrigacional.

\section{RIGHT OF OBLIGATIONS: OBLIGATION TO DO AND NOT TO DO.}

\section{ABSTRACT}

The purpose of this article is to reflect on the importance of the Obligatory Rights before society, specifically the right to do and not to do. The concepts and when applying these rights will be approached, aiming to demonstrate the complexity and importance of these rights in our contemporary society as much as the guarantee that it brings. The methodology included bibliographical research. The data presented were weighted using the hypothetical deductive method. It is concluded that the right to do and not to do is guarantees of compliance with what is due to him by right by competent norm.

Keywords: Obligation of Do's and Don'ts, Importance, Obligatory Law.

\section{INTRODUÇÃO}

As obrigações integram a vida do ser humano na sociedade, são importantes, tanto quanto seu cumprimento ou descumprimento que acarretam consequências são acondicionados pelo direito das obrigações, elencado no código civil brasileiro de 2002. O presente artigo tem o desígnio de discorrer o direito das obrigações, especificamente às obrigações de fazer e não fazer.

$\mathrm{O}$ direito das obrigações sobrevém de um complexo intelecto de normas que administram relações jurídicas de ordem patrimonial, no qual tem por astúcia, prestações de um sujeito em proveito de outro. Distinguindo então, aceitáveis aquelas junções jurídicas em que ao poder de decretar uma prestação, confiado à determinada pessoa, correspondendo um dever de prestar, adjudicado a ulterior. (DINIZ, 2016)

No direito obrigacional de fazer, por revelar-se numa agilidade do devedor, é a que acarreta maior contratempo ao credor, quando se enfrenta com descumprimento. É uma atividade, um emprego que conecta o devedor ao credor. O empreendimento tanto pode ser pagamento físico ou material, como pintar uma casa ou consertar um veículo. Pode estabelecer em uma atividade que raramente aparece bem, mas cuja substância é fundamentalmente jurídica (GOLÇALVES, 2011).

Agora no direito obrigacional de não fazer, o devedor compromete-se a uma abstenção. É 
um prestamento contrário, é a junção jurídica entre o credor e o devedor, no qual o devedor se compromete a não realizar tal ato, que poderia livremente fazer, se não fosse forçado em relação ao credor ou terceiro. O objeto das obrigações de não fazer, distingue-se por uma omissão autônoma, ou unida à outra obrigação positiva, a ordem de uma obrigação negativa motiva ao devedor uma privação que pode ou não, ser atida no tempo (VENOSA, 2017).

Retratando este modo, à importância e complexidade deste ramo do direito subscrito, relatando sua aplicabilidade e extensão real na sociedade consumista e capitalista dos dias atuais, bem como onde não pode ser pactuada e até onde alcança seus direitos compactuados entres as partes em uma simples relação de consumo cotidiana até mesmo em uma relação jurídica e o amparo legal que esta te provem.

Após breve reflexão, o estudo em tela, tem por objetivo refletir as perspectivas no que concerne ao direito das obrigações de fazer e não fazer, cuja importância reflete a discussão frente à obscuridade nas relações da sociedade, demostrando por meio de normas e legislação em vigor à complexidade e clareza existente no simples ato. Versando o estudo bibliográfico, leitura de leis, normas vigentes que concerne sobre o assunto do tema.

\section{METODOLOGIA}

Com a atual pesquisa, pretende-se, constituir em cima dos estudos bibliográficos, contornos de entendimentos nos conceitos e a sua importância vigente, das quais procederam na leitura e reflexão das normas, compondo o estudo em tela.

\section{DISCUSSÃO}

Não podemos conhecer nossos direitos e obrigações sem entendemos as normas que os definem. Assim, neste despretensioso trabalho, consideraremos as obrigações em suas generalidades e classificações, bem como as formas de cumprimento e descumprimento das mesmas. Será apresentado de forma prática um tema sobremaneira relevante, pois trata-se da importância de se compreender o que venha a ser Direito das Obrigações.

O direito das obrigações versa num complexo de normas que conduzem relações jurídicas de resolução patrimonial. Objetivando prestações de um ser em serventia de outro. Aponta, assim, regular vínculos jurídicos perante o poder de exigir uma prestação, adjudicado a alguém, corresponde uma obrigação de prestar, conferido a outrem. Essa área do direito civil debate dos vínculos entre credores e devedores, afastando de sua esfera relações de uma pessoa para com um objeto. O direito obrigacional aprecia as relações jurídicas de natureza pessoal, uma vez que sua substância é a prestação patrimonial, ou seja, a ação ou omissão da parte atrelada visando o interesse do credor, que tem o direito de exigir aquela ação ou omissão, de modo que, se ela não for feita espontaneamente, poderá mobilizar o poder jurídico para impetrar do patrimônio do devedor o crédito necessário à composição do prejuízo (VENOSA, 2017).

Segundo Gonçalves (2011, p. 17) “O direito das obrigações tem por objeto determinadas relações jurídicas que alguns denominam direitos de crédito e outros chamam direitos pessoais ou obrigacionais".

A expressão "obrigação" permite a compreensão de vários sentidos. Na sua mais resigna definição, o vocábulo exprime qualquer espécie de vínculo ou condicionamento da pessoa, quer seja no campo religioso, moral ou jurídico. Em outras palavras, na essência, o conceito é o mesmo: sujeição a uma regra de conduta, cuja autoridade é perfilhada ou forçosamente imposta.

A obrigação deve ser vista no tocante como o que une e garante o cumprimento da relação jurídica ou negocial entre as partes ou pessoas, ressalvando que não se tem apenas direito, mas também, obrigações entrelaçadas com os direitos.

Diniz (2016, p. 20) destaca: 
A grande importância do direito das obrigações nos dias atuais, ante a frequência de relações jurídicas obrigacionais. Deveras, o homem moderno vive numa "sociedade de consumo" onde os bens ou novos produtos da tecnologia moderna lhe são apresentado mediante uma propaganda tão bem elaborada que o leva a sentir necessidades primarias ou voluptuárias nunca antes experimentadas, como, p. ex., a de substituir um carro novo por um "zero km" que, embora supérfluo, vira satisfazer um anseio de status.

O direito obrigacional em seu tocante e a base na relação jurídica, diante que a sociedade gira em torno de relações de consumo de serviços, bens, entre outros. Deste modo dando garantia e suporte a tal sistema econômico.

Venosa (2017, p. 8 e 9) mostra que:

O Direito das Obrigações dá o suporte econômico da sociedade, porque é por meio dele que circulam os bens e as riquezas e escoa-se a produção. Segundo Orlando Gomes (1978:10), cada vez mais, no mundo contemporâneo, avulta a importância dos patrimônios constituídos quase exclusivamente de títulos de crédito, que são obrigações.

Em uma sociedade consumista, há disposição crescente de pulverização das relações obrigacionais. A todo tempo, a publicidade e a propaganda estimulam o consumo. Da precisão mais imprescindível ao fator mais supérfluo, o ser humano está continuamente consumindo diante disto está sempre se socorrendo do Direito das Obrigações. Em todas as atividades, da produção à repartição de serviços e bens, imiscui-se o direito obrigacional (VENOSA, 2017).

A obrigação de fazer atrela o devedor à prestação de um serviço ou ação positiva, material ou imaterial, próprio ou de terceiro, em favorecimento do credor ou de outrem. Essa relação obrigacional tem por desígnio qualquer procedimento humano, licito e admissível, do devedor ou de outro a despesas daquele, seja a prestação de ocupação físico ou material, seja a concretização de serviço intelectual, artístico ou cientifico, podendo ser, ainda, a execução de certo ato ou negocio jurídico, que não configura cumprimento de algum trabalho.

Gagliano e Pamplona F. (2016, p. 92) articula "Nas obrigações de fazer interessa ao credor a própria atividade do devedor".

Esse ramo do direito pode ser o fato fungível ou infungível, o que acarretara a possibilidade ou não do serviço ser prestado por terceiro quanto à prestação do fato. A obrigação de fazer será fungível toda via não presente restrição negocial no aspecto de que o trabalho seja concretizado por outrem. Assim, não obstante a construção de uma varanda com o pedreiro "Martins" para levantar e aumentar seu diâmetro em volta da casa, nada atalha se as circunstâncias do negócio não apontarem em sentido oposto que a execução da obra seja realizada pelo seu colega "Hudson". Em eventos como esse, diz-se que a obrigação não foi pactuada em aplicação à pessoa do devedor.

Obrigação de não fazer ocorre quando o devedor arca o compromisso de abster-se de alguma ação, que poderia exercer livremente se não se tivesse obrigado para acatar interesse jurídico do credor ou de outem. Caracteriza-se, logo, por uma abstenção de uma ação, por artifício do devedor, em proveito do credor ou de terceiro.

Gagliano e Pamplona F. (2016, p. 101) pronuncia “A obrigação de não fazer tem por objeto uma prestação negativa, um comportamento omissivo do devedor".

A despeito de a liberdade negocial prevalecer notadamente no Direito das Obrigações, 
devendo ser observado que não serão ponderadas lícitas as obrigações de não fazer que contravenham princípios de ordem pública e afrontem garantias fundamentais. Assim, pressupõese, não se carecem considerar válidas obrigações negativas como as seguintes: de não transitar por determinadas ruas, de não casar, de não trabalhar, de não sair da cidade, de não estudar, etc. Todas atingem, em última apreciação, direitos da personalidade e não são juridicamente aceitas.

Diante do exposto, observa-se a importância deste ramo do direito, bem como sua complexidade em um simples ato. A sociedade capitalista de hoje, tudo gira em torno da relação de consumo não apenas de bens também de serviços entre outros, logo, aparente a real importância de tais direitos para que se acredite e possa ter uma sociedade digna e unida onde o que e pactuado será comprido sendo esse uma garantia estabelecida por lei que impõe a outro o forçamento do inadimplemento na finalidade de saciar o vicio obrigacional.

\section{CONCLUSÃO}

Conforme se verifica, o direito das obrigações no tocante direito de fazer e não fazer se justifica no intuito de garantir a eficácia da relação entre os sujeitos com o devido cumprimento das obrigações, visando estabelecer uma relação confiável, buscando o melhor entre a sociedade num aspecto geral. Preexistente em nosso ordenamento jurídico.

Desta forma, conclui-se, dar a devida importância ao direito das obrigações nos dias de hoje, uma vez que o ser humano vive em um mundo capitalista e consumista, de serviços, bens entre outros; de diverso modo, onde se descobre presente as obrigações, próprio quando não se dá o necessitado valor ou respeito, pois sem a Obrigação não se apresenta garantia e direito. A despeito, não desempenha o que lhe é devido o indivíduo, e não exclusivamente por isso, mas em distintos aspectos, o Direito das Obrigações é um bem necessário ultimamente no ambiente social, prognosticado no ordenamento jurídico decorrendo do código civil brasileiro de 2002.

\section{REFERÊNCIAS BIBLIOGRÁFICAS}

BRASIL. Código civil brasileiro: LEI $\mathrm{n}^{\circ}$ 10.406, de 10 de janeiro de 2002. Disponível em: < http://www.planalto.gov.br/ccivil_03/leis/2002/L10406.htm >. Acesso em: 09 agosto 2017.

DINIZ, Maria Helena. Curso de direto civil brasileiro: teoria geral das obrigações. vol 2. 31. ed. São Paulo: Saraiva, 2016.

GAGLIANO, Pablo Stolze. ; PAMPLONA FILHO, Rodolfo. Novo curso de direito civil. vol 2. 17. ed. São Paulo: Saraiva, 2016.

GONÇALVES, Carlos Roberto. Direito civil brasileiro: teoria geral das obrigações. vol 2. 8. ed. São Paulo: Saraiva, 2011.

OLIVEIRA, Adriana Maria Evaristo Martinez de. et al. Normas e padrões para trabalhos acadêmicos e científicos da unoeste. 3 ed. Presidente Prudente: Universidade do Oeste Paulista, 2015. Disponível em: <http://www.unoeste.br/site/biblioteca/documentos/ManualNormalizacao.pdf?v=6>. Acesso em: 31 mar. 2017.

VENOSA, Silvio de Salva. Direito civil: obrigações e responsabilidade civil. vol 2. 17. ed. São Paulo: Atlas, 2017. 